\title{
Associations between Vitamin D and Type 2 Diabetes Mellitus: The Role of Vitamin D Receptor and Binding Protein
}

\author{
Eman S. Arafat1*, Inass M. Taha², Shahad W. Kattan³, Nouf Abubakr Babteen", Iman Fawzy ${ }^{5}$ \\ ${ }^{1}$ Medical Biochemistry and Molecular Biology Departement, Faculty of Medicine, Menoufia University, Al-Minufya, Egypt \\ ${ }^{2}$ Medicine Department, College of Medicine, Taibah University, Medina, KSA \\ ${ }^{3}$ Medical Laboratory Department, College of Applied Medical Science, Taibah University, Yanbu, KSA \\ ${ }^{4}$ Biochemistry Department, Faculty of Science, University of Jeddah, Jeddah, KSA \\ ${ }^{5}$ Mansoura Central Laboratories, Ministry of Health, Mansoura, Egypt \\ Email: *Dr.emimohamed@yahoo.com
}

How to cite this paper: Arafat, E.S., Taha, I.M., Kattan, S.W., Babteen, N.A. and Fawzy, I. (2020) Associations between Vitamin D and Type 2 Diabetes Mellitus: The Role of Vitamin D Receptor and Binding Protein. Journal of Diabetes Mellitus, 10, 222-235.

https://doi.org/10.4236/jdm.2020.104018

Received: July 22, 2020

Accepted: October 17, 2020

Published: October 20, 2020

Copyright $\odot 2020$ by author(s) and Scientific Research Publishing Inc. This work is licensed under the Creative Commons Attribution International License (CC BY 4.0).

http://creativecommons.org/licenses/by/4.0/

\begin{abstract}
Background: Type 2 diabetes mellitus (T2DM) is a chronic disease that is characterized by $\beta$-cell dysfunction and resistance for insulin. Vitamin D is necessary for insulin secretion so it is a crucial factor in the development of T2DM. This study was done to investigate the association between serum 25-hydroxy Vitamin D [25(OH)3D], VDR (Vitamin D receptor) and VDBP (Vitamin D binding protein) with type 2 diabetic patients compared to control subjects. Subjects and Methods: This study carried out 110 female patients who were previously diagnosed with type 2 diabetes and 110 age, sex and weight matched as controls. All participants were subjected to full history taking, clinical examination and assessment of fasting blood glucose, HbAlc, lipid profile, 25-hydroxy Vitamin D [25(OH)3D], VDR and VDBP. Results: Results showed that the level of $25(\mathrm{OH}) 3 \mathrm{D}$ was significantly lower in diabetic group compared to controls and was significantly negatively correlated with glycated hemoglobin, serum total cholesterol and low density lipoprotein cholesterol in type 2 DM. Decreasing Vitamin D level was significantly associated with decreasing VDR. No significant association was found between Vit D and VDBP levels. Conclusions: Vitamin D deficiency is frequent in diabetic patients and associated with poor control and outcome. This suggests a role of Vitamin D in the pathogenesis and control of T2DM. Serum VDBP in diabetes may be independent to the level of $25(\mathrm{OH}) 3 \mathrm{D}$ and needs further studies.
\end{abstract}




\section{Keywords}

Diabetes Mellitus, Type 2, 25-Hydroxy Vitamin D, Vitamin D Receptor, Vitamin D Binding Protein

\section{Introduction}

T2DM (Type-2 diabetes mellitus) is a chronic disease characterized by both $\beta$-cell dysfunction and increased insulin resistance [1]. The prevalence of T2DM continues to rise not only in developing countries, but also in developed countries now [2]. Several genetic and environmental factors can result in the progressive loss of $\beta$-cell function that manifests clinically as hyperglycemia. Once hyperglycemia occurs, patients are at risk of developing chronic complications [3]. Vitamin D is one of fat-soluble vitamin with steroid nucleus; it is described as a hormone and acts through intracellular receptors, which belong to the thyroid-steroid receptor superfamily [4].

Total serum levels of 25(OH)3D are a sensitive indicator for Vit D deficiency [5]. Vitamin D deficiency occurs worldwide due to insufficient sunlight and/or dietary intake common in adults. Vitamin D insufficiency is often detected in diabetic patients and it is believed to be linked to the disease development and severity [6].

The main carrier of Vitamin $\mathrm{D}$ in the serum is Vitamin D-binding protein (VDBP). It is a low-molecular weight glycoprotein $(58 \mathrm{kDa})$ which significantly predicts the bioavailability of active levels of $(25(\mathrm{OH}) 3 \mathrm{D})$ in the bloodstream [7].

The VDBP/25(OH)D complex formation, its filtration and reabsorption through receptor-mediated uptake in proximal renal tubular cells are vital for activation of Vitamin D [8].

Vitamin D is involved in skeletal development, thyroidal metabolism, immune response regulation, cardiovascular health and glucose-mediated insulin secretion via regulation of insulin receptor expression [9]. There is emerging evidence that low $25(\mathrm{OH}) 3 \mathrm{D}$ levels may be associated with increased risk of the MetS (metabolic syndrome), which represents a cluster of risk factors for type 2 diabetes [10]. Vitamin D supplementation may increase insulin production and secretion by acting via the regulation of the Vitamin D receptors dependent calcium and phosphorus metabolism cascade in pancreatic beta cells [11] [12]. There are several mechanisms proposed to relate the role of Vitamin D with the development of diabetes mellitus. Some of these include expression of Vitamin $\mathrm{D}$ receptors in the beta cells of pancreas, role of Vitamin D in maintenance of normal calcium homeostasis which plays a major role in insulin secretion, presence of Vitamin D receptor in skeletal muscle, improvement of insulin mediated glucose utilization following Vitamin D therapy, role of cytokines like Interleukin 6 and TNF alpha (Tumour Necrosis factor alpha) in causing insulin resistance and down regulation of cytokine production by Vitamin D [10]. Vitamin 
D may act on pancreatic beta cells in two possible pathways; Vitamin D may act directly to induce beta-cell insulin secretion by increasing the intracellular calcium concentration or it may mediate activation of beta-cell calcium-dependent endopeptidases to produce the cleavage that facilitates the conversion of pro-insulin to insulin [13].

In peripheral insulin-target tissues, Vitamin D might directly enhance insulin action through stimulation of the expression of insulin receptors [14].

\section{Subjects and Methods}

\subsection{Subjects}

This study was carried out by cooperation between Medical Biochemistry and medicine Departments, Faculty of Medicine, Taiba University \& Medical Biochemistry and Molecular biology Department, Faculty of Medicine, Menoufia University, in the period from December 2017 to February 2018. It included 220 females classified into two groups, Group 1: included 110 female patients with type II diabetes mellitus. Group 2: included 110 females of matched ages apparently healthy volunteers as controls.

Before sample collection, an informed written consent (approved by Human Rights \& Ethics Committee in Research at Taibah University, Madinah, KSA) was taken from all patients and controls. All subjects were subjected to detailed history taking (smoking, work, hypertension, family history of diabetes and duration of DM) physical and clinical examination, anthropometric measurements including waist circumference measurement and estimation of body mass index [BMI] was done by dividing body weight in kilograms by (height in meter ${ }^{2}$ ) and laboratory investigations including: fasting blood glucose (FBS), glycated hemoglobin (HbAlc), lipid profile \{serum total cholesterol (TC), high density lipoprotein cholesterol (HDL-c), triglycerides (TG) and low density lipoprotein cholesterol (LDL-c)\}, 25-hydroxyvitamin $\mathrm{D}(25(\mathrm{OH}) 3 \mathrm{D})$, Vitamin $\mathrm{D}$ receptor (VDR) and Vitamin D binding protein (VDBP)were done.

\subsection{Exclusion Criteria}

Included patients currently on oral steroid, endocrine disorders or patients on drugs that could have effect on bone (antiepileptic, corticosteroids, antidepressants, Vitamin D and calcium).

\subsection{Methods}

$8 \mathrm{ml}$ of venous blood were withdrawn from every subject after a $12 \mathrm{~h}$ fasting and dividing into three tubes: One $\mathrm{ml}$ of blood was transferred into sodium fluoride containing tube for enzymatic colorimetric determination of blood glucose. Blood glucose was determined by enzymatic colorimetric test, using Spinreact kit, SPAIN [15].

$6 \mathrm{ml}$ was transferred into a plain tube, left to clot, centrifuged for $10 \mathrm{~min}$ at 3000 R.P.M. The serum obtained was stored at $-80^{\circ} \mathrm{C}$ until colorimetric deter- 
mination of serum (TC) [16], LDL-c [17], HDL-c [18], TG [19], total serum levels of Vitamin D 25(OH)D, VDR and VDBP in samples were carried out by ELISA technique, using available commercial kit (CUSABIO and R\&D SYSTEMS) using horseradish peroxidase detection in accordance with the manufacturer's instructions (50,100 and $50 \mu \mathrm{L}$ of sample respectively were used). Samples were assayed as duplicates with a minimal detection level of $5 \mu \mathrm{g} / \mathrm{L}$ for $25(\mathrm{OH}) \mathrm{D}, 1.65 \mathrm{pg} / \mathrm{ml}$ for VDR, and $0.65 \mathrm{ng} / \mathrm{ml}$ for VDBP. Deficiency of vitamin was defined as if $25(\mathrm{OH}) \mathrm{D}$ level of less than $50 \mathrm{nmol} / \mathrm{L}$ ( $20 \mathrm{ng}$ per milliliter), insufficient Vitamin D if 25(OH)D levels were between 50 and $75 \mathrm{nmol} / \mathrm{L}(20$ - 30 ng per milliliter); and normal if levels of $25(\mathrm{OH}) \mathrm{D}$ levels were $75 \mathrm{nmol} / \mathrm{L}$ (30 ng per milliliter) to $100 \mathrm{nmol} / \mathrm{L}$. Serum levels of 25(OH)D greater than $150 \mathrm{nmol} / \mathrm{L}$. was defined as Vitamin D intoxication [20].

The remaining $1 \mathrm{ml}$ from the blood sample was placed in EDTA tube for quantitative colorimetric determination of glycated hemoglobin as percent of total hemoglobin using kits supplied by Teco diagnostics, USA [21].

\subsection{Statistical Analysis}

Data were fed to the computer and analyzed using IBM SPSS software package version 20.0. For qualitative data we used number and percent. The Kolmogorov-Smirnov test used to verify the normality of distribution. For quantitative data we used mean, standard deviation and median. Significance of the obtained results was at the $5 \%$ level.

\section{Results}

Diabetic cases were significantly associated with higher frequency of smoking, hypertension, higher BMI, wider WC, higher HA1C, TC, LDL, FBG and metabolic syndrome. Lower Vitamin D level was significantly associated with DM cases when compared to control group. VDR and VDBP did not differ significantly between both groups (Table 1 ).

Decreasing Vitamin D level was significantly associated with increasing BMI, WC, HA1C, TC, LDL, as well as with decreeing VDR. No significant association was found between Vit D and VDBP levels when DM cases were classified according to Vitamin D level (Table 2).

There were no significant differences found in Vitamin D level, VDR and VDBP according to studied data (nationality, work, smoking and hypertension) in DM cases (Table 3 ).

There was significant negative correlation between Vit D level and BMI, WC, HA1C, TC and LDL. There was significant negative correlation between VDR andHA1C, TC and LDL on the other hand; there was significant positive correlation between VDR and Vit D level (Table 4).

There was significant negative correlation VDBP level and VDR. Otherwise, no significant correlations were found between Vitamin D levels, VDR, VDBP with other studied parameters in DM cases (Table 4). 
Table 1. Demographic and laboratory parameters between the studied groups.

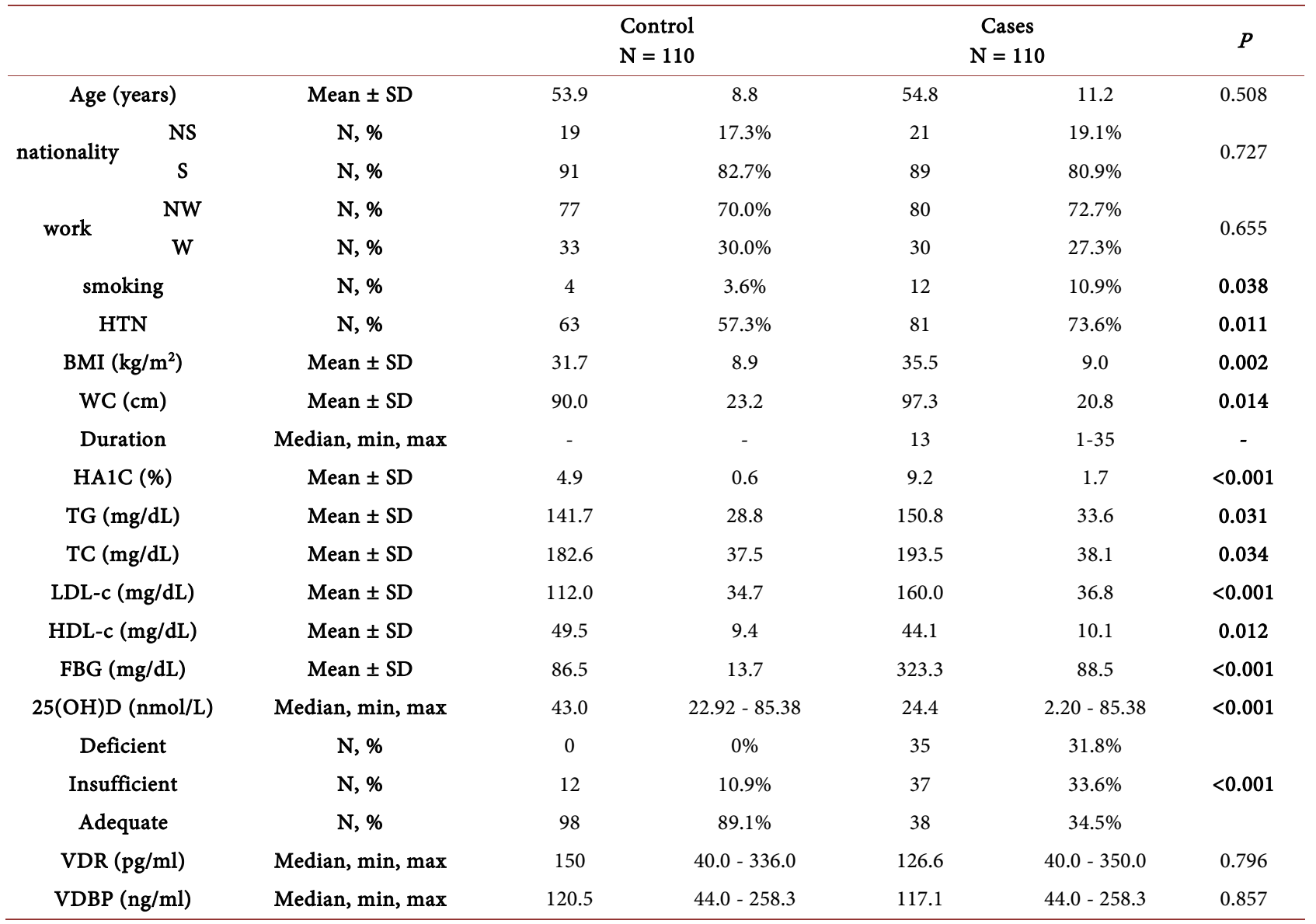

Table 2. Comparison of studied data between DM cases classified according to Vitamin D level.

\begin{tabular}{|c|c|c|c|c|c|c|c|c|c|c|c|c|c|}
\hline & & & \multicolumn{3}{|c|}{$\begin{array}{c}\text { Deficient } \\
\mathrm{N}=35\end{array}$} & \multicolumn{3}{|c|}{$\begin{array}{c}\text { Insufficient } \\
\quad \mathrm{N}=37\end{array}$} & \multicolumn{3}{|c|}{$\begin{array}{c}\text { Adequate } \\
\mathrm{N}=\mathbf{3 8}\end{array}$} & \multirow{2}{*}{$\begin{array}{c}P 1 \\
0.625\end{array}$} & \multirow{2}{*}{$\begin{array}{c}P 2 \\
0.371\end{array}$} \\
\hline \multicolumn{2}{|c|}{ Age (years) } & Mean \pm SD & 54.7 & & 6 & 53.7 & & 8 & & 6.2 & 13.7 & & \\
\hline \multirow{2}{*}{ nationality } & NS & $\mathrm{N}, \%$ & 7 & & $0 \%$ & 6 & 16. & $.2 \%$ & & 8 & $21.1 \%$ & \multirow{2}{*}{0.856} & \multirow{2}{*}{0.704} \\
\hline & $S$ & $\mathrm{~N}, \%$ & 28 & & $0 \%$ & 31 & 83. & $.8 \%$ & & 30 & $78.9 \%$ & & \\
\hline \multirow{2}{*}{ work } & NW & $\mathrm{N}, \%$ & 31 & & $6 \%$ & 22 & 59. & $.5 \%$ & & 27 & $71.1 \%$ & \multirow{2}{*}{0.021} & \multirow{2}{*}{0.774} \\
\hline & $\mathrm{W}$ & $\mathrm{N}, \%$ & 4 & & $4 \%$ & 15 & 40. & $.5 \%$ & & 11 & $28.9 \%$ & & \\
\hline \multicolumn{2}{|c|}{ smoking } & $\mathrm{N}, \%$ & 5 & & $3 \%$ & 3 & 8.1 & $1 \%$ & & 4 & $10.5 \%$ & 0.691 & 0.925 \\
\hline \multicolumn{2}{|c|}{ HTN } & $\mathrm{N}, \%$ & 29 & & $9 \%$ & 26 & 70. & $.3 \%$ & & 26 & $68.4 \%$ & 0.320 & 0.367 \\
\hline \multicolumn{2}{|c|}{ BMI(kg/m2) } & Mean \pm SD & 38.4 & & .5 & 35.5 & & .9 & & 2.8 & 9.0 & 0.026 & 0.022 \\
\hline \multicolumn{2}{|c|}{$\mathrm{WC}(\mathrm{cm})$} & Mean \pm SD & 101.9 & & 98 & 98.5 & & 0.3 & & 1.9 & 21.5 & 0.042 & 0.049 \\
\hline \multicolumn{2}{|c|}{ Duration } & Median, min, $\max$ & 13.0 & 1.0 & 30.0 & 10.0 & 2.0 & 35.0 & & 4.0 & $2.0 \quad 32.0$ & 0.732 & 0.514 \\
\hline \multicolumn{2}{|c|}{ HA1C (\%) } & Mean \pm SD & 11.1 & & .0 & 9.2 & & .5 & & 7.5 & 0.6 & $<0.001$ & $<0.001$ \\
\hline \multicolumn{2}{|c|}{$\mathrm{TC}(\mathrm{mg} / \mathrm{dL})$} & Mean \pm SD & 232.3 & & .3 & 200.3 & & .9 & & 1.1 & 21.2 & $<0.001$ & $<0.001$ \\
\hline \multicolumn{2}{|c|}{$\mathrm{LDL}(\mathrm{mg} / \mathrm{dL})$} & Mean \pm SD & 199.0 & & .4 & 165.1 & & 6 & & 9.2 & 20.5 & $<0.001$ & $<0.001$ \\
\hline \multicolumn{2}{|c|}{ FBG (mg/dL) } & Mean \pm SD & 332.0 & & 0.0 & 321.6 & & 2.3 & & 6.8 & 74.0 & 0.761 & 0.582 \\
\hline \multicolumn{2}{|c|}{$\operatorname{VDR}(\mathrm{pg} / \mathrm{ml})$} & Median, $\min , \max$ & 93.5 & 40.0 & 330.0 & 126.6 & 74.0 & 350.0 & 206.0 & 70.5 & 336.0 & $<0.001$ & $<0.001$ \\
\hline \multicolumn{2}{|c|}{$\operatorname{VDBP}(\mathrm{ng} / \mathrm{ml})$} & Median, $\min , \max$ & 120.6 & 44.0 & 171.2 & 166.9 & 100.6 & 172.7 & 105.2 & 63.4 & 258.3 & 0.062 & 0.080 \\
\hline
\end{tabular}


Table 3. Comparison of Vitamin D level, VDR, VDBP according to studied data in DM cases.

\begin{tabular}{|c|c|c|c|c|c|c|c|c|c|c|c|c|c|}
\hline \multirow{4}{*}{ Nationality } & \multirow{4}{*}{$\begin{array}{c}\text { NS } \\
\text { S }\end{array}$} & \multicolumn{4}{|c|}{ Vit D } & \multicolumn{4}{|c|}{ VDR } & \multicolumn{4}{|c|}{ VDBP } \\
\hline & & \multirow{3}{*}{$\begin{array}{c}\text { Median } \\
27.43 \\
24.44\end{array}$} & \multicolumn{2}{|c|}{ Range } & \multirow{3}{*}{$\begin{array}{c}\boldsymbol{P} \\
0.855\end{array}$} & \multirow{3}{*}{$\begin{array}{c}\text { median } \\
93.5 \\
126.6\end{array}$} & \multicolumn{2}{|c|}{ range } & \multirow{3}{*}{$\begin{array}{c}\boldsymbol{P} \\
0.967\end{array}$} & \multirow{3}{*}{$\begin{array}{c}\text { Median } \\
100.6 \\
120.6\end{array}$} & \multicolumn{2}{|c|}{ Range } & \multirow{3}{*}{$\begin{array}{r}P \\
0.214\end{array}$} \\
\hline & & & 2.20 & 68.79 & & & 40.0 & 350.0 & & & 44.0 & 258.3 & \\
\hline & & & 2.20 & 85.38 & & & 40.0 & 336.0 & & & 44.0 & 258.3 & \\
\hline \multirow{2}{*}{ Work } & NW & 23.9 & 2.20 & 85.38 & \multirow{2}{*}{0.120} & 117 & 40.0 & 336.0 & \multirow{2}{*}{0.255} & 120.6 & 44.0 & 258.3 & \multirow{2}{*}{0.670} \\
\hline & $\mathrm{w}$ & 27.4 & 2.20 & 85.38 & & 161.5 & 40.0 & 350.0 & & 100.6 & 44.0 & 258.3 & \\
\hline \multirow{2}{*}{ Smoking } & No & 24.88 & 2.20 & 85.38 & \multirow{2}{*}{0.628} & 126.6 & 40.0 & 350.0 & \multirow{2}{*}{0.950} & 111.7 & 44.0 & 258.3 & \multirow{2}{*}{0.106} \\
\hline & Yes & 23.68 & 2.20 & 85.38 & & 104.0 & 65.5 & 336.0 & & 161.2 & 63.4 & 258.3 & \\
\hline \multirow{4}{*}{ HTN } & No & 27.4 & 2.20 & 60.53 & \multirow{4}{*}{0.259} & 93.5 & 40.0 & 336.0 & \multirow{4}{*}{0.601} & 105.5 & 44.0 & 258.3 & \multirow{4}{*}{0.709} \\
\hline & Yes & 24.4 & 2.20 & 85.38 & & 126.6 & 40.0 & 350.0 & & 120.6 & 44.0 & 258.3 & \\
\hline & Yes & 25.3 & 2.20 & 68.79 & & 105.3 & 65.5 & 336.0 & & 124.9 & 44.0 & 258.3 & \\
\hline & Yes & 23.4 & 2.2 & 85.4 & & 115.8 & 40 & 350 & & 113.5 & 44 & 258.3 & \\
\hline
\end{tabular}

Table 4. Correlation of Vitamin D level, VDR, VDBP with other studied parameters in DM cases.

\begin{tabular}{ccccccc}
\hline & \multicolumn{2}{c}{ Vit D } & \multicolumn{2}{c}{ VDR } & \multicolumn{2}{c}{ VDBP } \\
\cline { 2 - 7 } & $\mathrm{p}$ & $\mathrm{r}$ & $\mathrm{p}$ & $\mathrm{r}$ & $\mathrm{p}$ & $\mathrm{r}$ \\
\hline Age (years) & 0.039 & 0.687 & 0.095 & 0.325 & -0.113 & 0.238 \\
BMI (kg/m $)$ & -0.270 & $\mathbf{0 . 0 0 4}$ & -0.066 & 0.494 & 0.02 & 0.84 \\
WC (cm) & -0.250 & $\mathbf{0 . 0 0 9}$ & 0.017 & 0.860 & 0.022 & 0.818 \\
HA1C (\%) & -0.930 & $<0.001$ & -0.452 & $<0.001$ & 0.001 & 0.999 \\
TC (mg/dL) & -0.911 & $<0.001$ & -0.473 & $<0.001$ & 0.002 & 0.984 \\
LDL (mg/dL) & -0.943 & $<0.001$ & -0.499 & $<0.001$ & -0.017 & 0.863 \\
FBG (mg/dL) & -0.073 & 0.450 & -0.098 & 0.307 & -0.039 & 0.685 \\
Duration & 0.065 & 0.501 & 0.002 & 0.997 & -0.025 & 0.797 \\
Vit D (nmol/L) & - & - & 0.515 & $<0.001$ & -0.038 & 0.696 \\
VDR (pg/ml) & - & - & - & - & -0.244 & 0.010 \\
\hline
\end{tabular}

At the cutoff point of 29.7 (RQ) Vit D can discriminate DM cases and control groups with a sensitivity of $65.5 \%$, a specificity of $89.1 \%$, positive predictive value $(85.7 \%)$, negative predictive value $(72.1 \%)$ and accuracy $(77.3 \%)$. While at a cutoff point of 115.75 (RQ), VDR can discriminate DM from control with a sensitivity of $44.5 \%$, a specificity of $63.6 \%$, positive predictive value (55.1\%), negative predictive value (53.4\%) and accuracy (54.1\%). At the cutoff point of 107.65 (RQ) VDBP can discriminate DM cases and control groups with a sensitivity of $43.6 \%$, a specificity of $61.8 \%$, positive predictive value $(53.3 \%)$, negative predictive value (52.3\%) and accuracy (52.7\%) (Table 5).

Smoking, HTN, higher BMI, WC, TC, LDL and lower Vit D were associated with risk of DM in univariable analysis. However, taking significant covariates into multivariable analysis revealed that higher TC, LDL and lower Vit D were considered as independent predictors of T2DM (Table 6). 
Table 5. Area under ROC curve and performance criteria of Vitamin D, VDR, VDBP levels for discrimination between DM cases and control groups.

\begin{tabular}{cccc}
\hline & Vit D & VDR & VDBP \\
\hline AUC (95\% CI) & $0.757(0.690-0.823)$ & $0.528(0.452-0.605)$ & $0.507(0.430-584)$ \\
Cut off & 29.7 & 115.75 & 107.65 \\
Sensitivity (\%) & 65.5 & 44.5 & 43.6 \\
Specificity (\%) & 89.1 & 63.6 & 61.8 \\
PPV (\%) & 85.7 & 55.1 & 53.3 \\
NPV (\%) & 72.1 & 53.4 & 52.3 \\
Accuracy (\%) & 77.3 & 54.1 & 52.7 \\
\hline
\end{tabular}

Table 6. Regression analysis for prediction of T2DM.

\begin{tabular}{ccccccccc}
\hline & \multicolumn{3}{c}{ Univariable } & \multicolumn{5}{c}{ Multivariable } \\
\cline { 2 - 9 } & $\mathrm{p}$ & OR & \multicolumn{2}{c}{$95 \% \mathrm{CI}$} & $\mathrm{p}$ & OR & 95\% CI \\
\hline Age (year) & 0.544 & 1.005 & 0.989 & 1.022 & & & & \\
smoking & $\mathbf{0 . 0 3 8}$ & 2.075 & 1.041 & 4.136 & 0.060 & 0.247 & 0.058 & 1.060 \\
Vit D (nmol/L) & $<0.001$ & 0.969 & 0.959 & 0.979 & $<0.001$ & 0.954 & 0.936 & 0.972 \\
VDR (pg/ml) & 0.773 & 1.000 & 0.998 & 1.002 & $<0.001$ & 4.534 & 2.408 & 8.534 \\
VDBP (ng/ml) & 0.839 & 1.000 & 0.996 & 1.003 & & & & \\
\hline
\end{tabular}

\section{Discussion}

Type 2 diabetes mellitus (T2DM) is a heterogeneous group of disorders resulting from the combination of genetic, behavioral, nutritional, and environmental risk factors. The pathogenesis of T2DM involves deficiency in insulin secretion and insulin resistance [22].

The nutritional risk factors play an important role in pancreatic $\beta$-cell physiology and their effects on insulin secretion [23]. Vitamin D is a critical and essential micronutrient for human health; it has a potential effect on pancreatic insulin secretion and insulin action [22].

Our study's aim is to study the association between serum 25-hydroxy Vitamin D [25(OH)3D], VDR \&VDBP and type 2 diabetic patients.

In the present study, analysis of the demographic and clinical data of two groups revealed that, smoking, hypertension and obesity were significantly high in diabetic patients group. These results agree with that reported by Mohammad et al. [24]. Several studies reported that elevations of both BMI and waist circumference are associated with increased incidence of diabetes [24] [25]. This is explained by the fact that obesity links to insulin resistance by increasing production of adipokines/cytokines, including tumor necrosis factor- $\alpha$, resistin and retinol-binding protein that contribute to insulin resistance [26].

In the present study, diabetic cases were significantly associated with higher TG, TC and LDL and significantly lower HDL. Several studies agree with our result [1] [22] [25] [26]. Dyslipidemia is a common feature of diabetes mellitus leads to cardiovascular complications [27]. 
This result can be explained by the fact that dyslipidemia association with atherosclerosis and the progression of atherosclerosis in diabetes is mainly due to the associated hyperglycemia, obesity and insulin resistance. Excess free fatty acids (FFA) liberation from adipose tissue occurs in T2DM due to insulin resistance. To a large extent lipoproteins hepatic metabolism is controlled by insulin [28].

The co-occurrence of metabolic risk factors in patient group (abdominal obesity, hyperglycemia, dyslipidemia and hypertension) suggested the existence of a metabolic syndrome.

In our study, the level of Vitamin D is significantly lower in type 2 diabetic patients than controls as shown in Figure 1(a). Many studies observed that Vit D level is significantly lower in type 2 diabetes [1] [29] [30]. This result can be explained by the fact that Vitamin D deficiency plays a role in the pathogenesis of T2DM. T2DM manifests as a result of insulin resistance, increased hepatic glucose production and $\beta$-cell failure. Vitamin D deficiency increases insulin resistance and decreases insulin secretion [31].

In our study, VDR and VDBP did not differ significantly between both groups as shown in Figure 1(b) \& Figure 1(c). This result in contrast that reported by Manal et al., who found both serum and urine VDBP levels were significantly elevated in patient than controls and this result explained by increased production of serum VDBP as a compensatory mechanism of increase losing of it in urine as a part of albuminuria that indicates tubular dysfunction in diabetes [32].

In our study, as shown in Figure 2 Vit D level showed significant negative correlation with BMI, WC, Wortsman et al. [33] have shown that both obese and normal weight persons' skin produces the same amount of Vitamin D under the same conditions, but that $57 \%$ less Vitamin D is absorbed into the circulation of obese persons, because of the higher amount of subcutaneous fat that traps the cholecalciferol. Also Vit D showed negative correlation with HA1C which was in agreement with many studies [1] [34] [35] and in contrary to other studies [36] [37].

Nwosu et al. showed that after three months of Vitamin D supplementation, there was a significant increase in $25(\mathrm{OH}) 3 \mathrm{D}$ in Type II diabetes mellitus patients and there was significant decrease in $\mathrm{HbAlc}$ from $8.5 \% \pm 2.9 \%$ at baseline to $7.7 \% \pm 2.5 \%$ in Type II diabetic patients [38].

In our study, Vit D level showed significant negative correlation with TC and LDL and metabolic syndrome. VDR and VDBP did not differ significantly according to presence or absence of metabolic syndrome. This result agrees with that reported by Shan et al., who found that $25(\mathrm{OH}) \mathrm{D}$ levels were significantly lower in subjects with obesity, high TG, type 2 diabetes, or metabolic syndrome compared to their control [39].

In our study, at cutoff 29.7 with AUC (0.757) Vit D can discriminate DM cases and control groups while for VDR, it was at cutoff point of 115.75 with AUC (0.528), also VDBP, at cutoff 107.65 with AUC (0.507) as shown in Figure 3. 


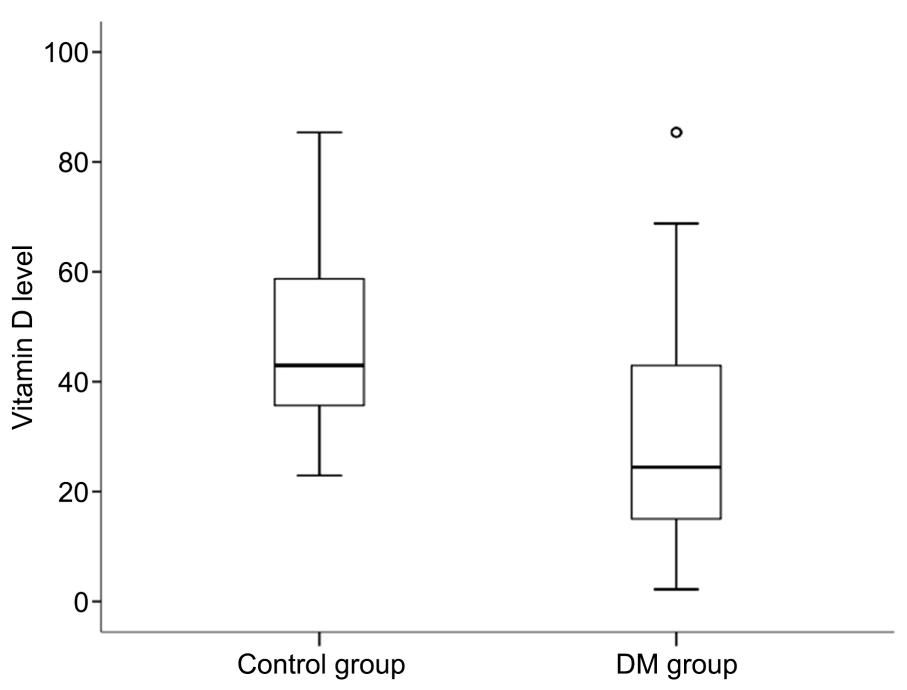

(a)

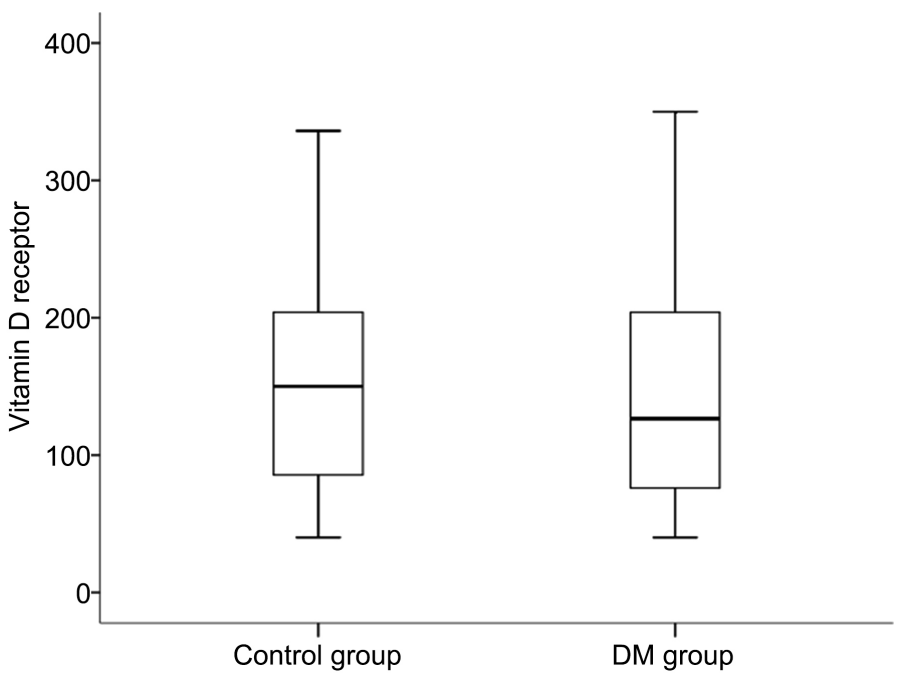

(b)

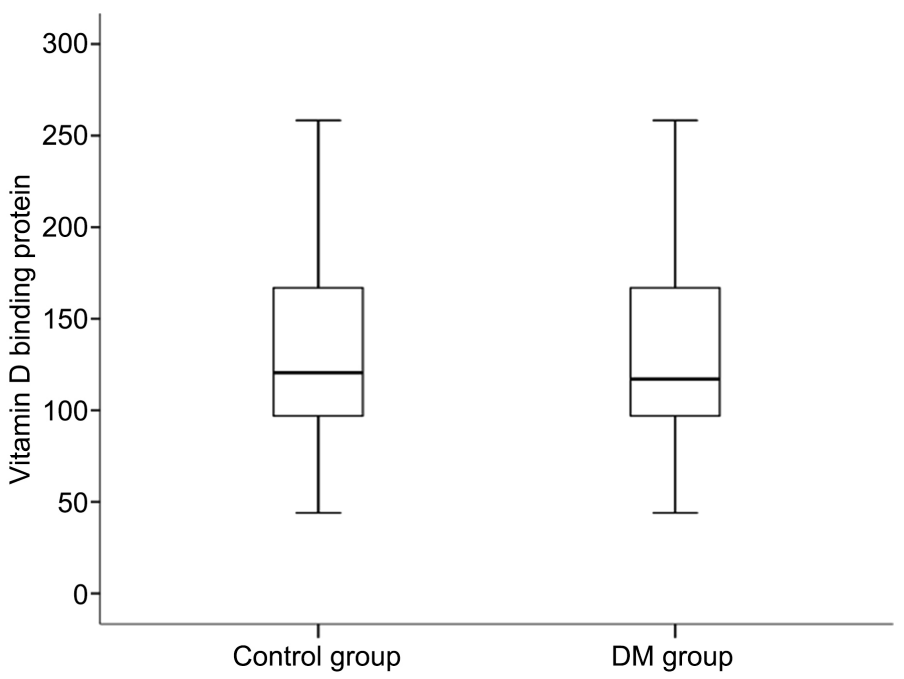

(c)

Figure 1. Levels of (a) Vitamin D, (b) Vitamin D receptor, (c) Vitamin D BP in DM cases and control groups. 

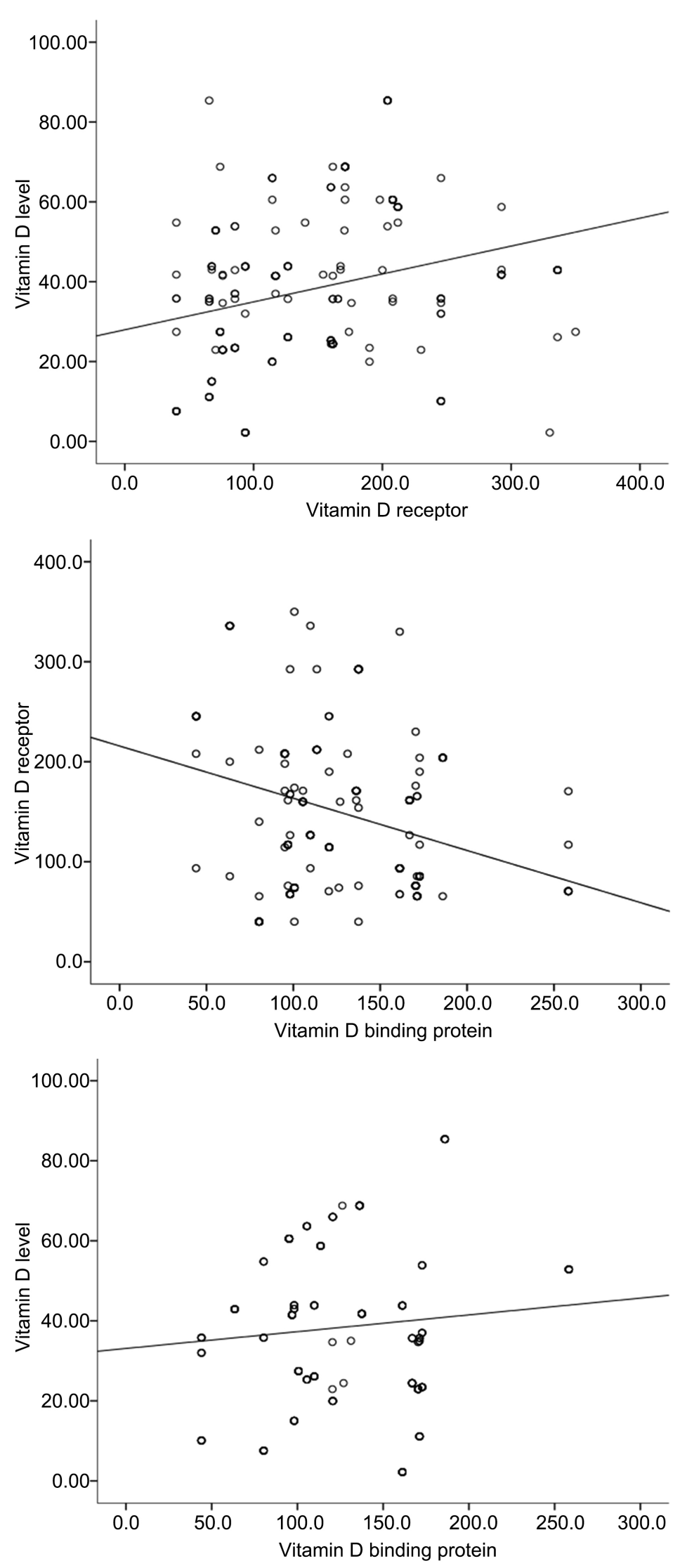

Figure 2. Correlations between Vitamin D, VDR, VDBP levels in DM cases. 


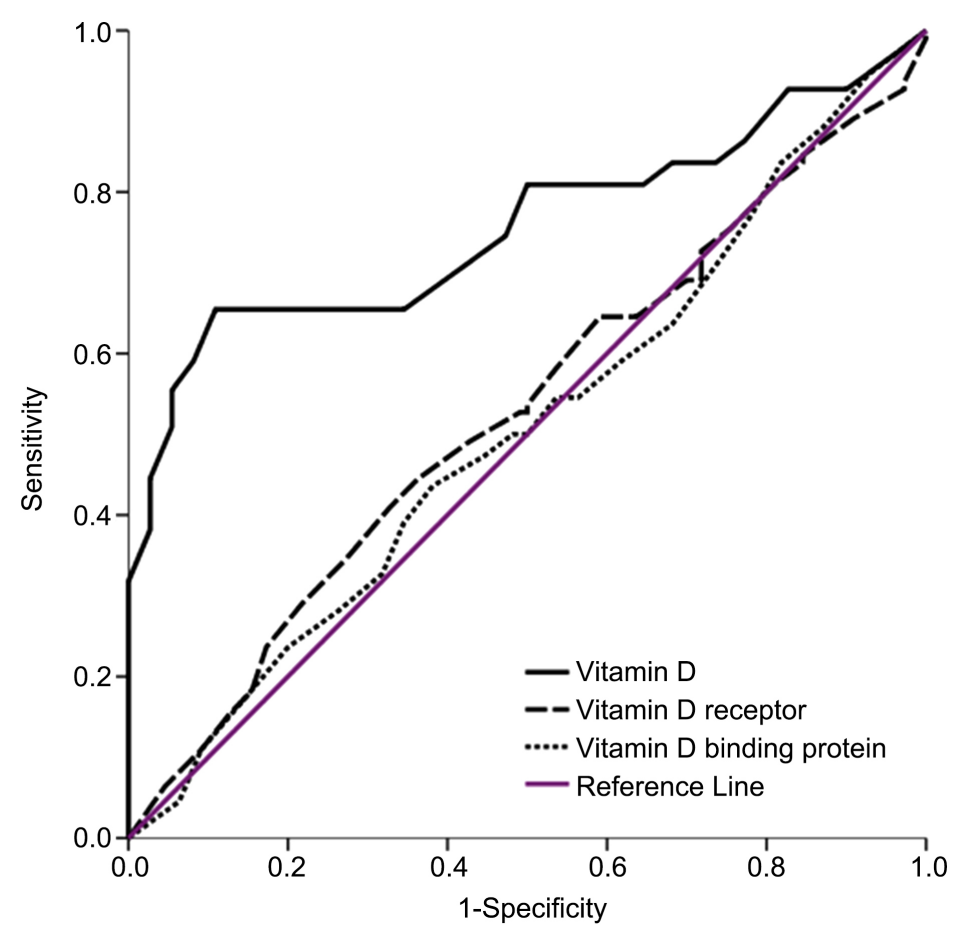

Figure 3. ROC curve of Vitamin D, VDR, VDBP levels for discrimination between DM cases and control groups.

Rui et al. demonstrated that ROC analysis of Vitamin D yielded AUC of 0.614 in the differentiation of diabetic patients from control with cutoff $(16.01 \mathrm{ng} / \mathrm{mL})$; Sensitivity: 66.73\%; Specificity: 55.72\% [40].

Manal et al. demonstrated that ROC analysis of $\mathrm{UVDBP}$ to detect patients with DN showed AUC of 0.807 in the differentiation of diabetic patients from control with cutoff (214 ng/mL); Sensitivity: 82.5\%; Specificity: 65\% [32].

In our study, both low Vit D and MetS were associated with risk of DM in univariable and multivariable analysis. Yun et al. showed that, logistic regression models revealed that low 25(OH)3D levels were independently predictive of the development of hyperglycemia, including prediabetes and T2DM. So $25(\mathrm{OH}) 3 \mathrm{D}$ concentration was a strong biomarker of diabetes risk [22].

The levels of Vitamin D, Vitamin D binding protein and Vitamin D receptors (VDR) have effect on the role of Vitamin D in stimulating insulin release [41].

Our study confirms the association between Vitamin D deficiency and type 2 diabetes.

\section{Conflicts of Interest}

The authors declare no conflicts of interest regarding the publication of this paper.

\section{References}

[1] Mogahed, M.M. (2018) Vitamin D Status in Patients with Type-2 Diabetes Mellitus in Riyadh City, Saudi Arabia. Kasr El Ainy Medical Journal, 24, 19-25. 
https://doi.org/10.4103/kamj.kamj_30_17

[2] Lu, D.-Y., Che, J.-Y., Yarla, N.S., Zhu, H., Lu, T.-R., Xu, B. and Puttas, S. (2019) Type 2 Diabetes Study, Introduction and Perspective. The Open Diabetes Journal, 9 , 1876-5246.

[3] Skyler, J.S., Bakris, G.L., Bonifacio, E., et al. (2017) Differentiation of Diabetes by Pathophysiology, Natural History and Prognosis. Diabetes, 66, 241-255. https://doi.org/10.2337/db16-0806

[4] Adams, J.S. and Hewison, M. (2010) Update in Vitamin D. The Journal of Clinical Endocrinology \& Metabolism, 95, 471-478. https://doi.org/10.1210/jc.2009-1773

[5] Khan, A.S, Sane, D.C., Wannenburg, T., et al. (2002) Growth Hormone, Insulin-Like Growth Factor and the Aging Cardiovascular System. Cardiovascular Research, 54, 25-35. https://doi.org/10.1016/S0008-6363(01)00533-8

[6] Ekmekcioglu, C., Haluza, D. and Kundi, M. (2017) 25-Hydroxyvitamin D Status and Risk for Colorectal Cancer and Type Diabetes Mellitus: A Systematic Review and Meta Analysis of Epidemiological Studies. International Journal of Environmental Research, 14, 127. https://doi.org/10.3390/ijerph14020127

[7] Abdella, N.A. and Mojiminiyi, O.A. (2018) Vitamin D-Binding Protein Clearance Ratio Is Significantly Associated with Glycemic Status and Diabetes Complications Ina Predominantly Vitamin D-Deficient Population. Journal of Diabetes Research, 2018, Article ID: 6239158. https://doi.org/10.1155/2018/6239158

[8] Mirković, K, Doorenbos, C.R.C., Dam, W.A., et al. (2013) Urinary Vitamin D Binding Protein: A Potential Novel Marker of Renal Interstitial Inflammation and Fibrosis. PLoS ONe, 8, e55887. https://doi.org/10.1371/journal.pone.0055887

[9] Jamka, M., Woźniewicz, M., Walkowiak, J., et al. (2016) The Effect of Vitamin D Supplementation on Selected Inflammatory Biomarkers in Obese and Overweight Subjects: A Systematic Review with Meta-Analysis. European Journal of Nutrition, 55, 2163-2176. https://doi.org/10.1007/s00394-015-1089-5

[10] Pittas, A.G., Lau, J., Hu, F.B., et al. (2007) The Role of Vitamin D and Calcium in Type 2 Diabetes. A Systematic Review and Meta-Analysis. The Journal of Clinical Endocrinology \& Metabolism, 92, 2017-2029. https://doi.org/10.1210/jc.2007-0298

[11] Handrail, F., Zakerkish, M., Karandish, M., et al. (2016) Association between Serum Vitamin D Level and Glycemic and Inflammatory Markers in Non-Obese Patients with Type 2 Diabetes. Iranian Journal of Medical Sciences, 41, 367-373.

[12] Talaei, A., Mohamadi, M. and Adgi, Z. (2013) The Effect of Vitamin D on Insulin Resistance in Patients with Type 2 Diabetes. Diabetology \& Metabolic Syndrome, 5, Article No. 8. https://doi.org/10.1186/1758-5996-5-8

[13] Shanthi, B., Revathy, C., Jagadeeshwaran, A., Devi, J.M., Parameshwari, P.J. and Stephen T. (2012) Serum 25(OH)D and Type 2 Diabetes Mellitus. Journal of Clinical and Diagnostic Research, 6, 774-776.

[14] Cimbek, A., Gursoy, G., Kirnap, N.G., Acar, Y., Erol, B., Ozasik, I. and Gungor, F. (2012) Relation of Serum 25 Hydroxy Vitamin D3 Levels with Insulin Resistance in Type 2 Diabetic Patients and Normal Subjects. Medicine Science, 1, 305-314. https://doi.org/10.5455/medscience.2012.01.8031

[15] Trinder, P. (1969) Determination of Glucose in Blood Using Glucose Oxidase with an Alternative Oxygen Acceptor. Annals of Clinical Biochemistry, 6, 24-25. https://doi.org/10.1177/000456326900600108 
[16] Remaley, A.T., Rifai, N. and Warnick, G.R. (2012) Lipids, Lipoproteins, Apolipoproteins and Other Cardiovascular Risk Factors. In: Carl, R.A. and David, E.B., Eds., Tietz Textbook of Clinical Chemistry and Molecular Diagnosis, 4th Edition, Saunders, 731-805.

[17] Friedewald, W.T., Levy, R.I. and Fredrickson, D.S. (1972) Estimation of the Concentration of Low-Density Lipoprotein Cholesterol in Plasma, without Use of the Preparative Ultracentrifuge. Clinical Chemistry, 18, 499-502.

https://doi.org/10.1093/clinchem/18.6.499

[18] Gordon, T., Zidek, W. and Amer, M. (1977) Determination of High Density Lipoprotein Cholesterol. Journal of Medicine, 42, 707-710.

[19] Fossati, P. and Prenciphe, L. (1982) Determination of Serum Triglyceride. inical Chemistry, 28, 207-210. https://doi.org/10.1093/clinchem/28.10.2077

[20] Heaney, R.P. and Holick, M.F. (2011) Why the IOM Recommendations for Vitamin D Are Deficient. Journal of Bone and Mineral Research, 26, 455-457. https://doi.org/10.1002/jbmr.328

[21] Gonen, B. and Rubenstien, A.H. (1978) Haemoglobin A1 and Diabetes Mellitus. Diabetologia, 15, 1-8. https://doi.org/10.1007/BF01219319

[22] Gao, Y., Zheng, T.P., Ran, X.W., Ren, Y., Chen, T., Zhong, L., Yan, D.G., Yan, F.F., Wu, Q.L. and Tian, H.M. (2018) Vitamin D and Incidence of Prediabetes or Type 2 Diabetes: A Four-Year Follow-Up Community-Based Study. Disease Markers, 2018, Article ID: 1926308. https://doi.org/10.1155/2018/1926308

[23] Moore, W.T., Bowser, S.M., Fausnacht, D.W., Staley, L.L., Suh, K.S. and Liu. D.M. (2015) Beta Cell Function and the Nutritional State: Dietary Factors That Influence Insulin Secretion. Current Diabetes Reports, 15, Article No. 76. https://doi.org/10.1007/s11892-015-0650-1

[24] Mohammad Hassan, J., Hamed, M., Koorosh, F., et al. (2016) Are Serum Levels of F2-Isoprostane and Oxidized-LDL Related to Vitamin D Status in Type 2 Diabetic Patients? A Case-Control Study. Reports of Biochemistry and Molecular Biology, 5, 26-32.

[25] Giril, D., Pintus, D., Burnside, G., Ghatak, A., Mehta, F., Paul, P. and Senniappan, S. (2017) Treating Vitamin D Deficiency in Children with Type I Diabetes Could Improve Their Glycaemic Control. BMC Research Notes, 10, Article No. 465. https://doi.org/10.1186/s13104-017-2794-3

[26] Eckel, R.H., Kahn, S.E., Eleferrannini, Goldfine, A.B., Nathan, D.M., Schwartz, M.W., Smith, R.J. and Smith, S.R. (2011) Obesity and Type 2 Diabetes: What Can Be Unified and What Needs to Be Individualized? Diabetes Care, 34, 1424-1430. https://doi.org/10.2337/dc11-0447

[27] Adu, E.M., Ukwamedu, H.A. and Oghagbon, E.S. (2015) Assessment of Cardiovascular Risk Indices in Type 2 Diabetes Mellitus. Tropical Medicine \& Surgery, 3, Article ID: 1000184 .

[28] Khattak, M., Nawaz, A., Anis, J. and Farwa, U. (2018) Dyslipidemia in Type 2 Diabetes Mellitus. The Journal of Islamic International Medical College, 13, 128-131.

[29] Rahman, M., Hosen, B., Faruk, O., Hasan, M., Yearulkabir, M and Howlader, Z.H. (2017) Association of Vitamin D and Vitamin D Binding Protein (DBP) Gene Polymorphism with Susceptibility of Type 2 Diabetes Mellitus in Bangladesh. Gene, 636, 42-47. https://doi.org/10.1016/j.gene.2017.09.008

[30] Gangji, S.N. (2017) Vitamin D Deficiency in Patients with Type 2 Diabetes Mellitus Leads to Vascular Complications. Health and Natural Sciences, 8. 
[31] Moreiraa, T.S. and Hamadeh, M.J. (2017) The Role of Vitamin D Deficiency in the Pathogenesis of Type 2 Diabetes Mellitus. Clinical Nutrition, 5, e155-e165. https://doi.org/10.1016/j.eclnm.2010.05.001

[32] Fawzy, M.S. and Abu Alsel, B.T. (2018) Assessment of Vitamin D-Binding Protein and Early Prediction of Nephropathy in Type 2 Saudi Diabetic Patients. Journal of Diabetes Research, 2018, Article ID: 8517929.

https://doi.org/10.1155/2018/8517929

[33] Wortsman, J., Matsuoka, L.Y., Chen, T.C., Lu, Z. and Holick, M.F. (2003) Obesity Is Associated with Vitamin D Insufficiency and Secondary Hyperparathyroidism. The American Journal of Clinical Nutrition, 77, 1342.

[34] Chaudhary, V., Bhaskar, N., Gupta, P.D., Lamichhane, A., Prasad, S. and Sodhi, K.S. (2016) Vitamin D and Glycated Hemoglobin (HbA1c) Levels in Type 2 Diabetes Mellitus. World Journal of Pharmaceutical Sciences, 5, 820-828.

[35] Zhang, J., Ye, J., Guo, G., Lan, Z., Xing, L., Pan, Z., et al. (2016) Vitamin D Status Is Negatively Correlated with Insulin Resistance in Chinese Type 2 Diabetes. International Journal of Endocrinology, 2016, Article ID: 1794894.

[36] Sadiya, A., Ahmed, S.M., Skaria, S. and Abusnana, S. (2014) Vitamin D Status and Its Relationship with Metabolic Markers in Persons with Obesity and Type 2 Diabetes in the UAE: A Cross-Sectional Study. Journal of Diabetes Research, 2014, Article ID: 869307.https://doi.org/10.1155/2014/869307

[37] Gao, S., Han, L.W., Fu, J.L., Li, G., Li, M. and Willi, S.M. (2018) Vitamin D Levels Are Associated with Risk Factors for Type 2 Diabetes and Metabolic Syndrome in Chinese Youths. Diabetes, 67, 1. https://doi.org/10.2337/db18-1365-P

[38] Nwosu, B.U. and Maranda, L. (2014) The Effects of Vitamin D Supplementation on Hepatic Dysfunction, Vitamin D Status, and Glycemic Control in Children and Adolescents with Vitamin D Deficiency and Either Type 1 or Type 2 Diabetes Mellitus. PLOS ONE, 9, e99646. https://doi.org/10.1371/journal.pone.0099646

[39] Olt, S. (2015) Relationship between Vitamin D and Glycemic Control in Patients with Type 2 Diabetes Mellitus. International Journal of Clinical and Experimental Medicine, 8, 19180-19183.

[40] He, R., Hu, Y.Y., Zeng, H., Zhao, J., Zhao, J.G., Chai, Y.M., Lu, F.D. and Liu, F. (2017) Vitamin D Deficiency Increases the Risk of Peripheral Neuropathy in Chinese Patients with Type 2 Diabetes. Diabetes/Metabolism Research and Reviews, 33, e2820. https://doi.org/10.1002/dmrr.2820

[41] Cade, C. and Norman, A.W. (1986) Vitamin D3 Improves Impaired Glucose Tolerance and Insulin Secretion in the Vitamin D Deficient Rat in Vivo. Endocrinology, 119, 84-90. https://doi.org/10.1210/endo-119-1-84 